EDITORIAL

\title{
Late opening of the infarct related artery: an open or shut case?
}

\author{
Z R Yousef, M S Marber, S R Redwood
}

Is there a place for the late opening of infarct related arteries, beyond the time window for myocardial salvage?

Heart 2005;91:561-562. doi: 10.1136/hrt.2004.047472

medical treatment who were shown to have persistent IRA occlusion $(\mathrm{n}=15)$. $^{5}$

In a larger study, Horie and colleagues, ${ }^{6}$ randomising patients to late intervention $(\mathrm{n}=44)$ or medical treatment $(\mathrm{n}=39)$ with occluded left anterior descending arteries (LAD) between one day and three weeks after anterior MI, demonstrated significant improvements in LV ESV and EF, and a significant reduction in combined clinical events at five years in the late angioplasty group. ${ }^{6}$ These data contrast with our own, which is at odds with the open artery hypothesis. In a similar study randomising 66 patients with single vessel disease (LAD occlusion) to delayed intervention (with stents) or medical treatment 26 days after transmural anterior MI, we demonstrated a significant increase in LV ESV in the late reperfused group compared to patients receiving optimal medical treatment at 12 months. ${ }^{7}$

\section{LARGEST INTERVENTIONAL TRIAL OF LATE IRA REPERFUSION}

More recently, Steg of the DECOPI (désobstruction coronaire en post-infarctus) investigators presented data from the largest randomised interventional trial of late IRA reperfusion to date at a hotline session of the 2003 European Society of Cardiology annual meeting in Vienna, Austria. No difference in a combined event rate of cardiac death, non-fatal MI, and non-fatal ventricular arrhythmia at three years was observed in patients undergoing late reperfusion ( $\mathrm{n}=109$, event rate $7.3 \%$ ) compared to patients treated medically $(\mathrm{n}=103$, event rate $8.7 \%$, $\mathrm{p}=0.64)$. Of note, this study involved a relatively low risk group of all comers, with an overall low event rate, and LAD occlusion was present in $<20 \%$. In a related study, a German group randomising 300 symptom-free patients 1-6 weeks post-MI to intervention or medical treatment where the IRA was either stenosed or occluded observed a 90\% combined event-free survival rate in the interventional group compared with $82 \%$ in the medical group ( $\mathrm{p}=\mathrm{NS}$ ). Furthermore, in the subgroup of patients with total occlusion of the IRA, combined event rates of $29.5 \%$ (late intervention group; $n=44$ ) versus $26.1 \%$ (medical group; $\mathrm{n}=42, \mathrm{p}=\mathrm{NS}$ ) were

See end of article for authors' affiliations .....................

Correspondence to: Dr Simon Redwood, Cardiothoracic Centre, St Thomas' Hospital, London SEl 7EH, UK; simon.redwood@ gstt.nhs.uk
In TAMI-6 (thrombolysis and angioplasty in myocardial infarction), late presenting patients were randomised to thrombolysis or placebo. Those with documented occluded IRAs 24 hours later underwent a second randomisation intervention $(\mathrm{n}=34)$ or medical treatment $(\mathrm{n}=37)$. At six months, left ventricular (LV) end systolic volume (ESV) increased by $9 \%$ in the late reperfusion group, and decreased by $12 \%$ in the medical group ( $p=N S$ ). Since this study was conducted in the pre-stent era, IRA patency was similar in the two groups at six months $(60 \%$ $v$ 40\%, respectively). ${ }^{4}$ The TOMIIS (total occlusion post-myocardial infarction intervention study) investigators demonstrated a significant improvement in left ventricular ejection fraction (EF) at four months post-MI in a highly selected subgroup of patients $(\mathrm{n}=12)$ with sustained IRA patency after randomisation to late intervention compared to similar patients receiving
Abbreviations: ESV, end systolic volume; IRA, infarct related artery; ISIS-II, second international study of infarct survival; LAD, left anterior descending coronary artery; $\mathrm{MI}$, myocardial infarction; SAVE, survival and ventricular enlargement; TAMI, thrombolysis and angioplasty in myocardial infarction; TIMI, thrombolysis in myocardial infarction; TOMIIS, total occlusion post-myocardial infarction intervention study 
seen. ${ }^{8}$ Interestingly, the investigators of this study failed to recruit their target of 800 patients as attending physicians were reluctant to randomise patients to the non-interventional arm, and patients were reluctant to consent to an interventional procedure in the absence of symptoms!

\section{OPEN ARTERY HYPOTHESIS REMAINS CONTROVERSIAL}

The open artery hypothesis therefore remains controversial. of the randomised studies to date, three have shown no significant benefits between invasive versus conservative strategies for the treatment of occluded IRAs late after MI, one study strongly supports an invasive strategy, and our data strongly refutes the open artery hypothesis.

In this issue of Heart, Piscione and colleagues ${ }^{9}$ describe their single centre observations in a non-randomised cohort of 65 symptomatic patients referred for angioplasty to a chronic total occlusion ( $>6$ months duration) after transmural MI. ${ }^{9}$ Their examination of the open artery hypothesis involved comparing functional and clinical data in 35 patients successfully reperfused (TIMI flow grade 3 ) versus 30 patients with suboptimal recanalisation of the IRA (TIMI flow $<3$ ). The investigators report significant improvements in echo derived EF, ESV, and regional wall motion abnormalities in the reperfused group, but no difference in the same measures in the suboptimally reperfused group. In addition, the authors observed significantly more major adverse cardiac outcomes in the incompletely revascularised group compared to the successfully reperfused group at three years.

These results are interesting and in support of the open artery hypothesis. Several issues need to be addressed, however. The study by Piscione and colleagues involved symptomatic patients. Thus the IRA is likely to have subtended a significant volume of viable tissue, and therefore a benefit from myocardial salvage cannot be excluded. Although this contradicts the open artery hypothesis (which in its purest form proposes that any benefit from late reperfusion is independent of myocardial salvage), the present study is probably more applicable in the clinical setting where coronary artery occlusion is an acute-onchronic process, and often occurs in the presence of multivessel disease and pre-existing collateralisation, resulting in the presence of viable myocardium in the peri-infarct zone. Our own data, for example, suggest that significant benefits from late intervention with respect to MRI derived indices of LV remodelling are achievable in patients with significant residual myocardial viability demonstrated by stress dobutamine magnetic resonance imaging (MRI).$^{10}$

\section{TIMING OF LATE REPERFUSION}

A further point of interest relates to the timing of late reperfusion. In the study by Piscione and colleagues, ${ }^{9}$ the intervention was performed very late after MI (six months post-MI), while in the randomised studies described above, intervention was performed earlier $(<6$ weeks after MI). Scar formation and infarct healing is usually completed within six weeks of MI. ${ }^{11}$ Thus, if late reperfusion benefits by mechanisms independent of myocardial salvage-for example, by influencing the extent of infarct expansion, extracellular matrix reorganisation, and regional inflammationreperfusion within six weeks of MI is expected to yield the greatest benefits. ${ }^{12}$ This is suggested by Pfisterer and colleagues $^{13}$ who reported improved MRI derived indices of LV remodelling in patients undergoing reperfusion of the LAD within two weeks of transmural anterior MI, but not in patients undergoing similar intervention three months after MI. ${ }^{13}$

The door of the open artery hypothesis therefore remains ajar. It is likely that in cases where significant amounts of hibernating or viable tissue remain within the infarct zone, mechanical revascularisation in the subacute phase of MI will lead to long term clinical benefits. Evidence to support such a strategy in routine clinical practice at the present time, however, is circumstantial and limited. Before late revascularisation can be adopted as a routine procedure for patients remaining symptom-free after transmural MI, the results of an ongoing international multi-centre study (the occluded artery trial; scheduled to complete enrolment in 2005) needs scrutinising.

\section{Authors' affiliations}

Z R Yousef, Department of Cardiology, Good Hope Hospital, Birmingham, UK

M S Marber, Department of Cardiology, The Rayne Institute, Kings College London, London, UK

S R Redwood, Department of Cardiology, Guys and St Thomas' Hospitals, London, UK

\section{REFERENCES}

1 Boersma E, Maas AC, Deckers JW, et al. Early thrombolytic treatment in acute myocardial infarction: reappraisal of the golden hour. Lancet 1996;348:771-5

2 White H. Mechanism of late benefit in ISIS-2. Lancet 1988;2:914.

3 Lamas GA, Flaker GC, Mitchell G, et al. Effect of infarct artery patency on prognosis after acute myocardial infarction. The survival and ventricular enlargement investigators. Circulation 1995;92:1101-9.

4 Topol EJ, Califf RM, Vandormael M, et al. A randomized trial of late reperfusion therapy for acute myocardial infarction. Thrombolysis and angioplasty in myocardial infarction-6 study group. Circulation 1992;85:2090-9.

5 Dzavik V, Beanlands DS, Davies RF, et al. Effects of late percutaneous transluminal coronary angioplasty of an occluded infarct-related coronary artery on left ventricular function in patients with a recent ( $<6$ weeks) Q-wave acute myocardial infarction (total occlusion post-myocardial infarction intervention study (TOMIIS) - a pilot study). Am J Cardiol 1994;73:856-61.

6 Horie H, Takahashi M, Minai K, et al. Long-term beneficial effect of late reperfusion for acute anterior myocardial infarction with percutaneous transluminal coronary angioplasty. Circulation 1998;98:2377-82.

7 Yousef ZR, Redwood SR, Bucknall CA, et al. Late intervention after anterior myocardial infarction: effects on left ventricular size, function, quality of life, and exercise tolerance: results of the open artery trial (TOAT study). J Am Coll Cardiol 2002; 40:869-76.

8 Zeymer U, Uebis R, Vogt A, et al. Randomized comparison of percutaneous transluminal coronary angioplasty and medical therapy in stable survivors of acute myocardial infarction with single vessel disease: a study of the Arbeitsgemeinschaft Leitende Kardiologische Krankenhausarzte. Circulation 2003; 108: 1324-8.

9 Piscione F, Galasso G, De Luca G, et al. Late reopening of an occluded infarct related artery improves left ventricular function and long term clinical outcome. Heart 2005;91:646-51.

10 Bellenger NG, Yousef Z, Rajappan K, et al. Infarct zone viability influences ventricular remodelling following late recanalisation of an occluded infarct related artery. Heart 2005;91:478-83.

11 Fishbein MC, Maclean D, Maroko PR. Experimental myocardial infarction in the rat: qualitative and quantitative changes during pathologic evolution. Am J Pathol 1978;90:57-70.

12 Yousef ZR, Marber MS. The open artery hypothesis: potential mechanisms of action. Prog Cardiovasc Dis 2000;42:419-38.

13 Pfisterer ME, Buser P, Osswald S, et al. Time dependence of left ventricular recovery after delayed recanalization of an occluded infarct-related coronary artery: findings of a pilot study. J Am Coll Cardiol 1998;32:97-102. 